\title{
Light and Electron Microscopic Features of the Kidney in Hedgehog (Hemiechinus auritus)
}

\section{Abolghasem Nabipour *, Hesam Dehghani}

Department of Basic Sciences, Faculty of Veterinary Medicine, Ferdowsi University of Mashhad, Mashhad, Iran 91779-48974

Received October 2011, accepted for publication January 2012

\section{Abstract}

Kidneys are important organs that regulate the volume and composition of body fluids. In this study, some renal light and electron microscopic features were examined in 5 hedgehogs (Hemiechinus auritus). The right kidneys were processed for routine light microscopy, while the left kidneys were prepared for transmission electron microscopy.

The kidney in this animal is beanshaped and has a smooth surface. Light microscopy analysis revealed that the renal corpuscles are small dark red spherical bodies that have an average diameter of $82 \mu \mathrm{m}$. Podocytes contained a clear nucleus and had several large cytoplasmic primary processes, from which smaller secondary and tertiary processes emanate. The epithelium of the proximal convoluted tubule was simple cuboidal, which was covered at the apical surface by a brush border formed by sparse microvilli.
Narrow intercellular spaces were observed between the cell membranes in the proximal convoluted tubule. Both descending and ascending loops of Henle were long and extended from cortex into the medulla. The distal convoluted tubule consisted of a simple cuboidal epithelium. These cells were covered by short microprojections at the apical surface, while at the basolateral side they had extensive plasma membrane infoldings with a few mitochondria. The juxtaglomerular (JG) and macula densa cells were present at the junction of distal tubules with afferent arterioles. The collecting ducts were lined with simple cuboidal epithelium. The cells of the medullary collecting duct had a few short apical microprojections and randomly oriented mitochondria. In this report, some histological and physiological features of individual components of nephrons in hedgehog have been discussed. 


\section{Key Words}

hedgehog, histology, kidney, light

microscopy, electron microscopy

\section{Introduction}

The waste products of the nutrient metabolism, including nitrogenous materials and inorganic salts are actively removed from the body by kidneys and salt glands in different organisms (Holz and Raidal, 2006).

The structure of nephrons in different animals tightly correlates with the ability of the animal to conserve ions and/or water (Samuelson, 2007). Understanding the structure of the kidneys and especially the interrelationship of the renal tubules and renal vasculature is essential to appreciate the diverse functions of the kidney (Dellmann and Eurell 1998). Structure and ultrastrcuture of nephron components in mammalian insectivores including hedgehogs is not completely known.

The purpose of this research was to provide some basic information about light and electron microscopic features of the kidney in the longeared hedgehog from the Erinaceinae family (spiny hedgehogs). During the hibernating season (November-April) the hedgehog neither eats nor drinks. It spends about 80 percent of the time in hibernation at about $5^{\circ} \mathrm{C}$ body temperature. The

hibernation is interrupted every one to two weeks by arousal periods, during which the hedgehog rewarms to $34{ }^{\circ} \mathrm{C}$ (Clausen and Toresund, 1971). We studied both histological and ultrastructural features of the kidneys in five male hedgehogs in summer season (July-August). The results were compared with the available information from kidneys in domestic animals. The information presented in this paper can be used by zoologists, histologists, physiologists and in any related field of research on the kidneys, particularly in exotic animals.

\section{Materials and Methods}

Five adult male long-eared hedgehogs (Hemiechinus auritus) (Fig 1) with an average body weight of 357 $\mathrm{g}$ were captured in the summer from the agricultural farms around the city of Mashhad, Northeast of Iran. (Fig 2). The climate type of the study area is arid to semi-arid; with $255 \mathrm{~mm}$ annual precipitation and 14.2 Celsius degrees mean annual temperature. The mean Air temperature changes from 0 Celsius in the January to 25 Celsius in July. Relative humidity changes from 45 percents in dry months to 75 percents in humid winter months.

Captured hedgehogs were euthanized by intra-peritoneal administration of sodium pentobarbital (20 
$\mathrm{mg} / \mathrm{kg}$ ). The kidneys were removed from the abdomen immediately after euthanasia and were examined for their gross features.

\section{Light Microscopy}

In all animals the right kidneys were processed for routine light microscopy. Briefly, after making transverse sections, kidney pieces were placed in $10 \%$ neutral buffered formalin (Merck; Darmstadt, Germany). The fixation solution was refreshed after 24 hours and samples were kept in the fresh solution at $4^{\circ} \mathrm{C}$ for 72 hours. Samples were further processed for dehydration in a series of graded ethanol steps of $30,50,70,95 \%$, and $100 \%$ ethanol with incubations for 2 hours at each step. Dehydrated tissue samples were placed in xylene for 2 hours and embedded in paraffin wax. Sections $(5 \mu \mathrm{m})$ were prepared using a RM2145 microtome (Leica; Germany) and were stained with hematoxylin and eosin, periodic acid-Schiff (PAS) and Alcian blue ( $\mathrm{pH} 2.5)$. The latter two stains were used for distinguishing muco-substance materials within the tissue. The stained sections were observed by a CX21 light microscope (Olympus; Japan). Microphotographs were taken with an Olympus (U-TVO 63XC) camera mounted on the microscope.

\section{Electron Microscopy}

J. Vet. Anat.
The left kidneys from three hedgehogs were processed for transmission electron microscopy. Tissue samples were removed in approximately $1 \times 1 \mathrm{~mm}^{3}$ pieces and immediately transferred into the solution of $2.5 \%$ glutaraldehyde in $0.1 \mathrm{M}$ phosphate buffer for 2 hours at room temperature. The fixation solution was refreshed after 2 hours and samples were kept in the fresh solution at $4^{\circ} \mathrm{C}$ overnight and washed in buffer, $\mathrm{pH}$ 7.2. Then, tissue samples were subjected to a post-fixation step with Dalton's osmium tetroxide (TAAB, UK) for $1 \frac{1}{2}$ hours at $4^{\circ}$ and washed in buffer, $\mathrm{pH}$ 7.2. After that, tissue samples were placed in a series of graded ethanol steps of 70 , 90,95 , and two changes in $100 \%$ ethanol, with incubations for 5 minutes at each step, and 10 minutes in $100 \%$ ethanol. Dehydrated tissues were infiltrated with propylene oxide and embedded in Araldite 502 epon resin (TAAB, UK). Sections of $90 \mathrm{~nm}$ were obtained by a Leica ultramicrotome (Ultracut R, Austria), were picked up onto the finder grids, and stained with uranyl acetate and lead citrate. Then the specimens were viewed in a $912 A B$ LEO transmission electron microscope (Germany).

\section{Results}

Both right and left kidneys in all studied animals were bean-shaped 
and had a smooth surface. The kidneys in the studied hedgehogs possessed a thin capsule of loose connective tissue composed of collagen fibers and scattered smooth muscle fibers. The parenchyma consisted of the outer dark red cortex and the inner lighter colored medulla.

In addition to the cortical labyrinth and medullary rays, the cortex contained renal corpuscles. The renal corpuscles were small spherical and dark red bodies that had an average diameter of $82 \mu \mathrm{m}$. They were composed of glomerular capillary tuft, mesangium, and a PAS-Alcian blue positive Bowman's capsule (Fig 3, 4).

Bowman's capsule surrounded the glomerulus. It consisted of an outer parietal layer and an inner visceral layer. The parietal layer was formed of a simple squamous epithelium. The visceral epithelial cells, or podocytes, covered the outer surface of the glomerular capillaries. The podocyte contained a nucleus and was the origin of several large, primary processes from which smaller secondary and tertiary processes emanated. The smallest of these are called foot processes or pedicels. The secondary and tertiary foot processes of one cell interdigitated with those of the adjacent cells. The narrow spaces between the foot processes are called filtration slits, which were bridged by the slit diaphragm (Figs 5, 6). The glomerular capillary tuft was a network of branching and anastomosing capillaries. These capillaries were lined by an extremely thin layer of fenestrated endothelium. The glomerular basement membrane (GBM) separated the endothelial cells in its inner surface from the podocytes. The GBM was composed of three layers; the lamina rara interna, the layer adjacent to the endothelium; the lamina rara externa, the layer adjacent to the podocytes; and the lamina densa, the layer between the laminae rara (Fig 5, 6).

The proximal convoluted tubule was the major component of the cortical labyrinth. It was lined by a simple cuboidal epithelium (Fig 3). The proximal convoluted tubules entered the medullary rays (Fig 7 ). The apical surface in the proximal convoluted tubule was covered by a brush border formed by not extensive projections of the apical plasma membrane called microvilli. This finding was in contrast to that in other animals. The cytoplasm contained a central nucleus and numerous mitochondria (Fig 8). Adjacent cells were joined by junctional complexes. Narrow intercellular spaces were found between cell membranes.

The thin portion of the loop of Henle began at the end of the proximal tubule and extended into the inner 
medulla (Fig 9). Thus, it seems that nephrons contain long loops in the long-eared hedgehog. The hairpin turn occurred in the inner medulla. The thin ascending limb extended from the turn to the region of transition to the thick ascending limb at the border of the inner and outer medulla. The thin limbs had a simple squamous epithelium. In comparison to the adjacent capillaries, the nuclei in the thin limb of Henle had a greater protrusion into the lumen (Fig 9).

The distal convoluted tubule consisted of a simple cuboidal epithelium that was shorter than the epithelial cells of the proximal convoluted tubule. The cells of the macula densa tended to have a more crowded and taller appearance than the rest of the cuboidal cells of the tubule (Fig 3). The apical surface of the distal convoluted tubule was covered by short micro projections. Also, extensive basolateral plasma membrane infoldings with a few mitochondria were present. The juxtaglomerular (JG) cells contained granules with various sizes which apparently were filled with renin (Fig 10).

The cortical collecting duct was a straight tubule segment in the medullary ray (Fig 7 ). It descended through the medulla. The collecting ducts were lined with simple cuboidal epithelium (Fig 9). The cells of the medullary collecting duct had a few short apical microprojections and randomly oriented mitochondria (Fig 11).

\section{Discussion}

In the long-eared hedgehog, the shape of the kidneys is similar to that in small ruminants and carnivores. In contrast, in horses, the left kidney is bean-shaped and the right kidney is heart-shaped. In large ruminants, both kidneys are oval and have multiple lobes which are visible on the surface. In pigs, the kidneys are smooth, elongated, and flattened (Samuelson, 2007; Eurell and Frappier 2006). The kidneys in elephants are composed of $8 \pm 2$ lobes separated by fine interlobar septa (Maluf, 1995).

In all domestic species, the cortex lies outside the medulla (Samuelson, 2007). Similar to the hedgehog, the capsule of the kidney has some smooth muscle fibers in the dog, horse and pig. Whereas, kidney capsules in the ruminants have a distinct smooth muscle layer. There is no smooth muscle in the kidney capsule of the cat (Bacha and Wood, 1990).

The renal corpuscle varies in size among species. Our findings indicate that corpuscles have an average diameter of $82 \mu \mathrm{m}$ in the hedge- 
hog. However, larger animals tend to have larger corpuscles. For example, horse corpuscles average $220 \mu \mathrm{m}$ in diameter, whereas cat corpuscles average $120 \mu \mathrm{m}$ in diameter (Eurell and Frappier 2006). The mean glomerular diameter in rats ranges from 89.02 to 116.23 $\mu \mathrm{m}$, with a mean of $101.41 \mu \mathrm{m}$ (Pinto and Brewer 1974). The number of glomeruli per kidney in the elephants is approximately $15 \times 10^{6}$. In adult elephants the glomerular mass is $4.9 \pm 0.5 \%$ of the renal parenchyma and $6.7 \pm 0.3 \%$ of the cortex. Anatomically, an elephant's kidney appears to be able to concentrate urine only moderately. Their kidneys tend to resemble those of the manatee but not of the dugong (Maluf, 1995).

The general features of the onehumped camel's kidney are not different from those mammals, but show some unique modifications to pertain its remarkable drinking capacity and the production of hypertonic urine under extreme conditions of water deprivation. The kidney of camel has thicker renal capsule, higher number of glomeruli and wider medulla than for other studied mammals (Jarrar, 2005). Besides the many features common to other mammalian kidneys, the nephron of the camel is unique in having an unusually thick basal lamina under- lying the epithelial cells of the nephron, the thickest being found in part of the parietal layer of Bowman's capsule and the thin limb of the loop of Henle. In the latter, the membrane usually appears lamellated and contains numerous tiny vesicles. In other parts of the nephron, the basal lamina usually has a homogenous appearance (Safer et al, 1988).

In mammals, the apical brush border and the basolateral plasma membrane infoldings significantly increase the surface area of the cell of the proximal convoluted tubule and thus permit the high rates of transepithelial transport (Eurell and Frappier, 2006). In addition, brush border microvilli play a mechanosensory function in which fluid dynamic torque is transmitted to the actin cytoskeleton and modulates $\mathrm{Na}^{+}$absorption in proximal tubules (Du et al., 2004). Lower density of microvilli in the hedgehog may suggest a decreased efficiency of water and ions reabsorption in this tubular component of the nephron.

In the proximal tubule cells, close association of the mitochondria with the plasma membrane provides a ready source of energy for adenosine triphosphate (ATP)-dependent transport proteins located in the basolateral plasma membrane. In the 
long-eared hedgehog, proximal tubule cells contained an extensive array of mitochondria. In other species, endocytotic apparatus including numerous apical vesicles, endosomes, lysosomes, and peroxisomes, that contain oxidative enzymes for metabolism of toxic substances, are abundant in the proximal straight tubule. We were not able to observe the above mentioned structures in hedgehog. In cats, the proximal convoluted tubule cells contain numerous lipid droplets. In dogs, these cells contain similar lipid droplets and thus the medullary rays appear lighter than the surrounding parenchyma (Eurell and Frappier 2006; Dellmann and Brown, 1981). We could not detect this feature in hedgehog either.

Wide intercellular spaces coupled with extensive cell membrane infoldings in proximal tubule of some species is a characteristic of cells that have a high ion and water reabsorption capacity (Cunningham and Klein 2007). For example, the avian proximal tubule absorbs about 70 percent of the filtered volume of water, which depends on active reabsorption (Reece, 2009).

Our observation in the hedgehog including the narrow intercellular spaces and not extensive basal membrane infoldings may also relate to our previous suggestion that reabsorption capacity in the early components of nephron is lower in this species.

In the hedgehog the loop of Henle was long as has been reported in many desert animals. The thin limbs closely interact with adjacent interstitial vasculature and provide an osmolarity gradient that increases from the outermost portion of the outer zone of the medulla to the innermost portion of the inner zone (Samuelson, 2007). With this increased gradient, desert mammals including the desert hedgehog are able to produce hyperosmotic urine. In contrast, most birds do not contain a loop of Henle (Reece, 2009). The longer the loop of Henle usually indicates the ability to produce more concentrated urine (Abdalla, 1979). A dehydrated camel can replace water within minutes of drinking, and some of this water is quickly absorbed into the bloodstream. With water in the bloodstream, ADH declines and the kidney will return to normal renal function within 30 minutes of drinking (Etzion and Yagil, 1986).

Similar to the majority of mammals, in hedgehog, the intralobular vein was not present (Fig 3) and the distal tubules were randomly oriented throughout the cortex. In birds, the majority of distal tubules are clus- 
tered around the intralobular vein (Casotti and Richardson, 1993). In the dog and cat fat globules are present in the cells of distal tubule (Dellmann and Brown,1981). The distal tubule has many mitochondria and basolateral plasma membrane foldings, reflecting its high capacity for active solute transport (Reece, 2004).

The cells of the JG complex including JG and macula densa cells were present in the hedgehog kidney. Also, numerous granules (Fig 10) were observed in the cytoplasm of JG cells. The JG cells are modified smooth muscle cells in the wall of afferent arterioles close to the glomerulus (Bacha and Wood, 1990).

The JG cells after stimulation by macula densa, release rennin (accumulated as cytoplasmic granules) in response to reduced renal perfusion pressure. Renin catalyzes plasma angiotensinogen conversion to angiotensin I, which is converted to angiotensin II in many tissues. Angiotensin II increases intravascular fluid volume by stimulating sodium (and thus water) reabsorption in the proximal tubule and by stimulating adrenal aldosterone secretion, which enhances sodium uptake in the collecting duct (Eurell and Frappier, 2006). In the horse, the macula densa commonly consists of a stratified layer of cells (Bacha and
Wood, 1990). In the one-humped camels, the cellular structure, and organization of the juxtaglomerular apparatus appears to be similar to that of other mammals (Moussa, 1982).

A simple cuboidal epithelium was present throughout the collecting duct. However, a few short apical microprojections and randomly oriented mitochondria were observed in the medullary segment. In carnivores, the epithelium of the collecting duct remains low cuboidal throughout, whereas in ungulates, the epithelium in the medullary portions can be simple columnar or even transitional near the papillary apex (Eurell and Frappier, 2006). We were not able to distinguish two cell types of the collecting duct. In domestic animals, two types of cells compose the epithelium lining the collecting duct: principal cells (light cells) and intercalated cells (dark cells). These cells are important in maintaining the body's acid-base balance (Eurell and Frappier, 2006; Samuelson, 2007). In birds, the cytoplasm of each cortical collecting tubule cell contains a basal nucleus and the accumulations of mucopolysaccharide in the cytoplasm. Therefore, the mucopolysaccharide is stained positive with Alcian blue and PAS. Similarly, the distal tubules contain mucopolysaccharide 
and also are involved in producing concentrated urine by reabsorbing water from the tubular lumen. In addition, they are also known to secrete mucin, which may aid in eliminating uric acid from the kidney (Casotti,2001). Alcian blue and PAS stainings in hedgehog samples did not result any positive reactions, indicating the absence of the mucopolysaccharide in collecting ducts.

\section{Acknowledgements}

This research has been supported by a grant (No. 1483) from the Research Council of the Ferdowsi University of Mashhad.

\section{References}

Abdalla, M. A (1979): Morphometric observations on the kidney of the camel (Camelus dromedarius). J. of Anat., 129: 45-50.

Bacha, W. J. and Wood, J. L. M (1990). Color atlas of veterinary histology. Lea \& Febiger, Philadelphia.

Casotti, G (2001): Effects of season on kidney morphology in house sparrows. J. Experimental Biol., 204: 12011206.

Casotti, G. and Richardson K. C
(1993): A qualitative analysis of the kidney structure of Meliphagid honeyeaters from wet and arid environments. J. Anat., 182: 239247.

Clausen, L. and Toresund, A

(1971): Electrolyte distribution and renal function in the hibernating hedgehog. Acta Physiol. Scand., 83: 4-12.

Cunningham, J. G. and Klein, B. G (2007): Textbook of Veterinary Physiology. Saunders, St. Louis.

Dellmann, H. D. and Brown, E. M (1981): Textbook of veterinary histology. Lea \& Febiger, Secon Edition, Philadelphia.

Dellmann, H. D. and Eurell, J (1998): Textbook of veterinary histology. Lippincott Williams \& Wilkins, Fifth Edition, Philadelphia, USA.

Du, Z.; Duan, Y.; Yan, O.; Wein stein, A. M.; Weinbaum, S. and Wang, T (2004): Mechanosensory function of microvilli of the kidney proximal tubule. PNAS, 101: 1306813073.

Etzion, Z. and Yagil, R (1986): Re nal function in camels (Camelus dromedarius) following rapid rehydration. Physiol. Zool., 59: 558-562. 
Eurell, J. A. and Frappier, B. L (2006): Dellmann's Textbook of veterinary histology. Blackwell Publishing, Sixth Edition, Ames, USA.

Holz, P. H. and Raidal, S. R (2006): Comparative renal anatomy of exotic species. Vet. Clin. North. Am. Exot. Anim. Pract., 9: 1-11.

Jarrar, B. M (2005): Histochemical characterization of dehydrogenases in the nephron of the one-humped camel (Camelus dromedarius). Pakistan J. of Biol. Sci., 8: 1055-1059.

Maluf, N. S. R (1995): Kidney of el ephants. Anat. Rec., 242: 491-514.

Moussa, M. H. G (1982). Histomor phological study of the JG complex of the one-humped camel (Camelus dromedarius). Anatomia Histologia Embryologia, 11: 1982: 5055.

Pinto, J. A. and Brewer, D. B

(1974): Glomerular morphometry. I. Combined light and electron microscope studies in normal rats. Lab Inves, 30: 657-663.

Reece, W. O (2004): Dukes' physic ology of domestic animals. Cornell University Press, Twelfth Edition, Ithaca.

Reece, W. O (2009): Functional anatomy and physiology of domestic animals. WileyBlackwell, Fourth Edition, Ames, USA.

Safer, A. M.; el-Sayed, N .K.; AboSalem, K. and Al-Shaer, R. (1988): Ultrastructure of the nephron of the one-humped camel (Camelus dromedarius).J.Morphol.,198: 287-301. Samuelson, D. A (2007): Textbook of veterinary histology. Saunders, St. Louis.

\footnotetext{
* Correspondence and reprint requests should be addressed to

A. Nabipour

Email: nabipour@ferdowsi.um.ac.ir or gnabipour@gmail.com, Tel/Fax: 0098 (511) 8763852
} 


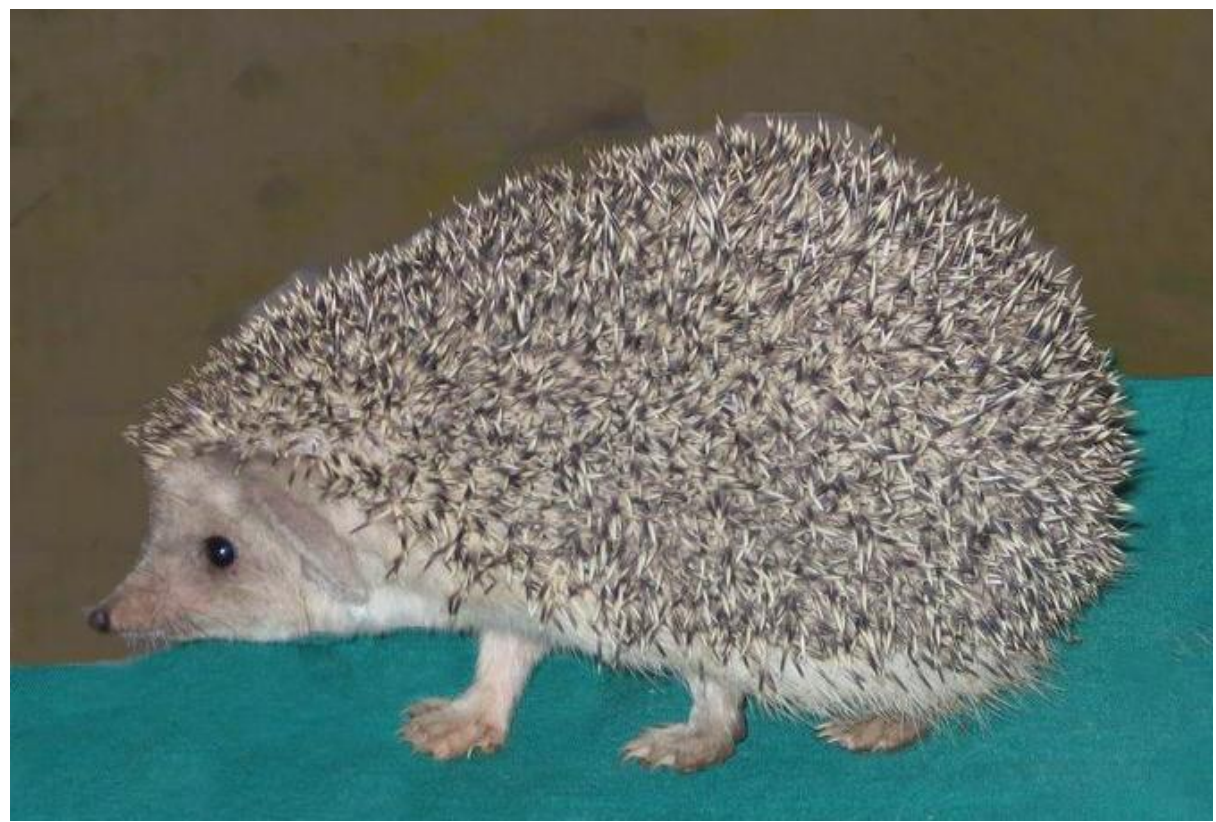

Fig (1): The Hemiechinus auritus species of hedgehog studied in this research.

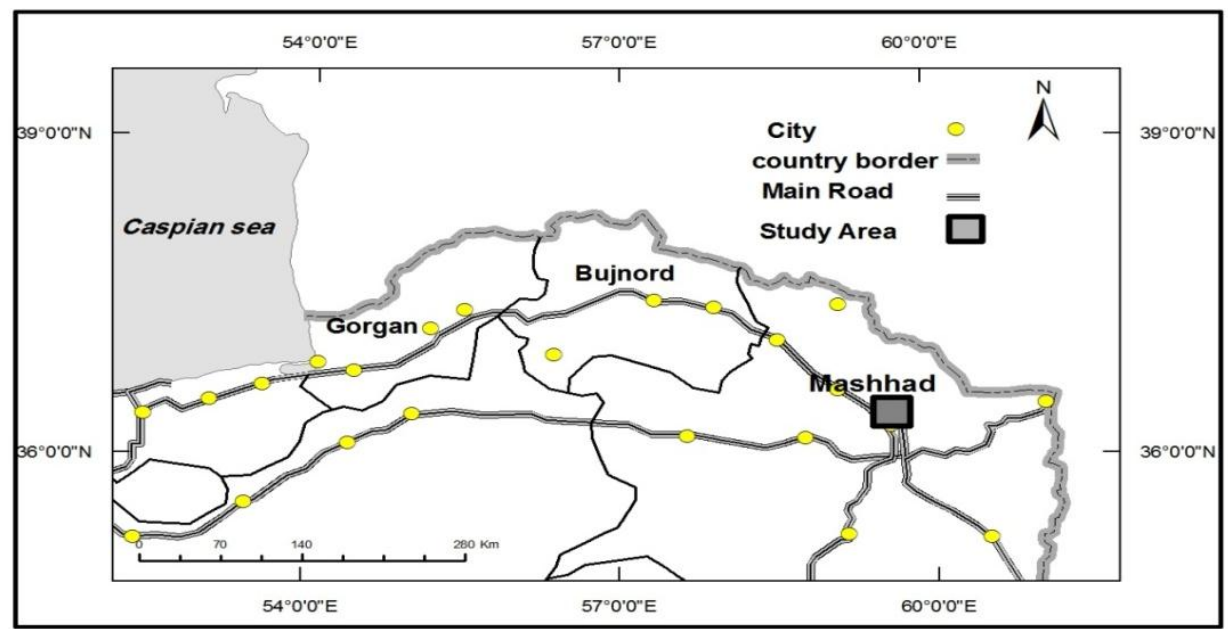

Fig (2): The place of capturing the hedgehogs (Mashhad), Iran 


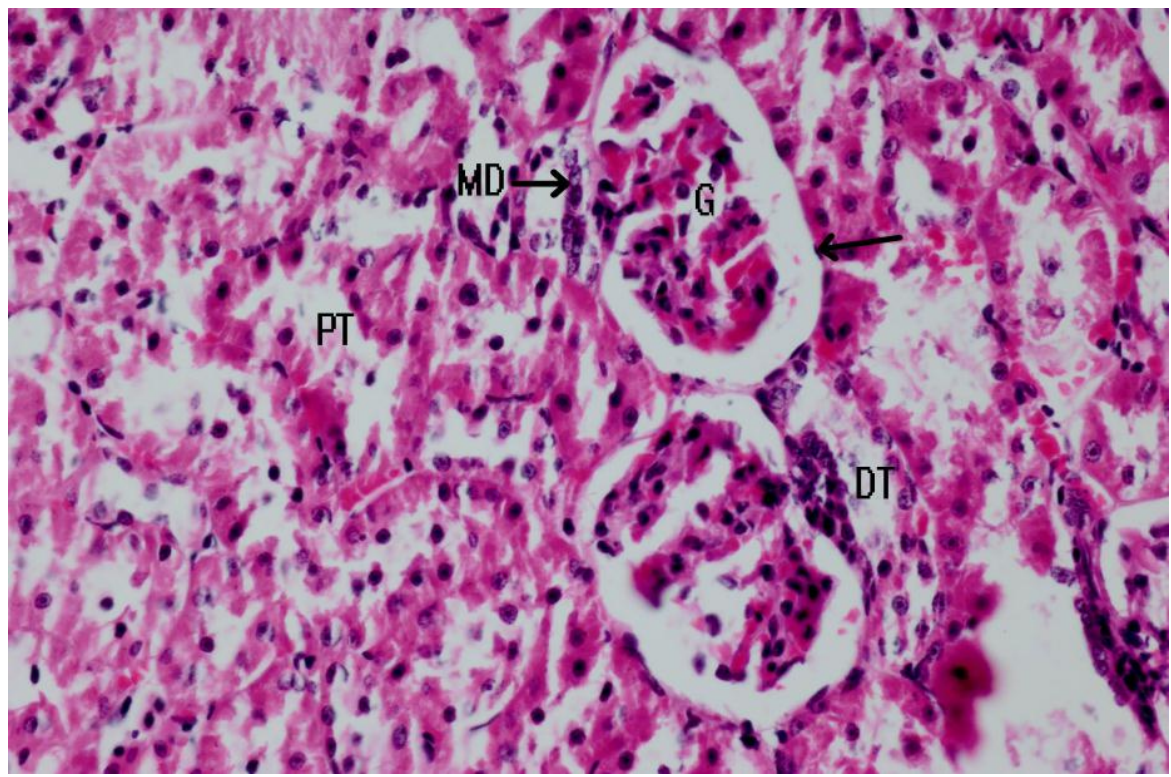

Fig (3): Proximal convoluted tubule (PT), distal convoluted tubule (DT), Macula densa (MD), Glomerulus (G), Parietal layer of Bowman's capsule (arrow). Hematoxylin and Eosin stain, $\times 640$.

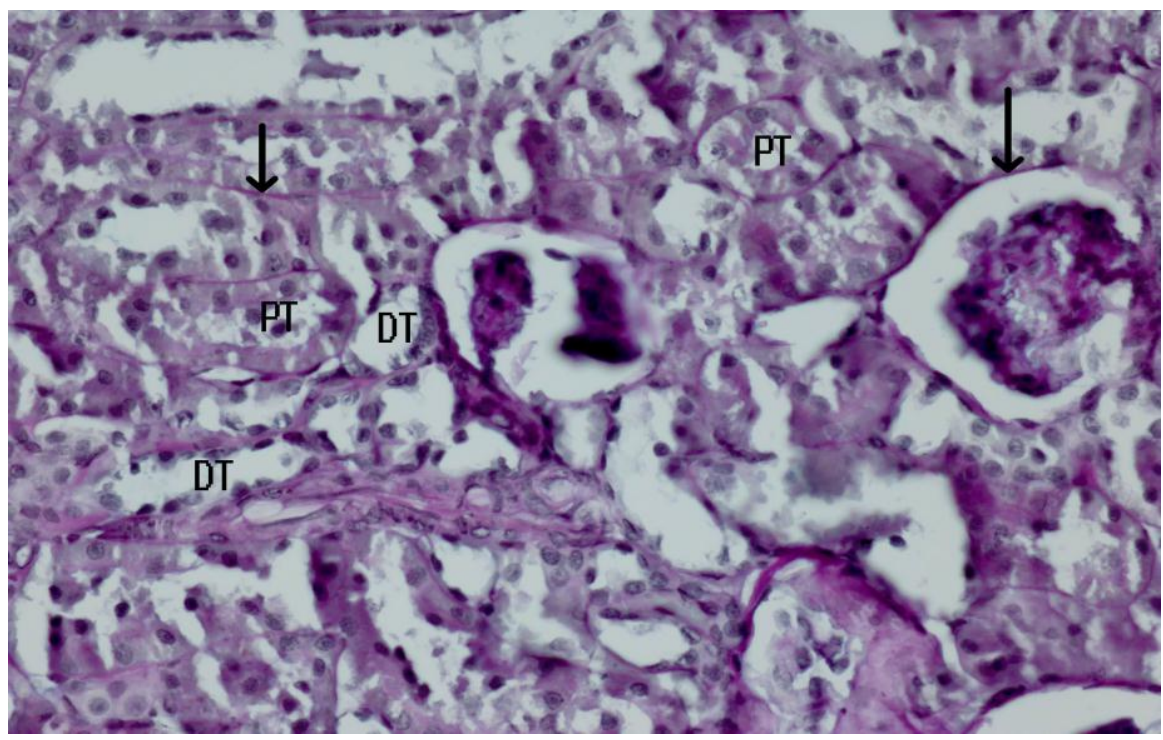

Fig (4): Light micrograph of a renal cortex of hedgehog stained for carbohydrates to reveal the glomerular basement membrane including the glomerular capsule. Proximal convoluted tubule (PT); distal convoluted tubule (DT), glomerular basement membrane and the basement membrane around the tubules (arrows). PAS-Alciane blue stain, $x$ 640. 


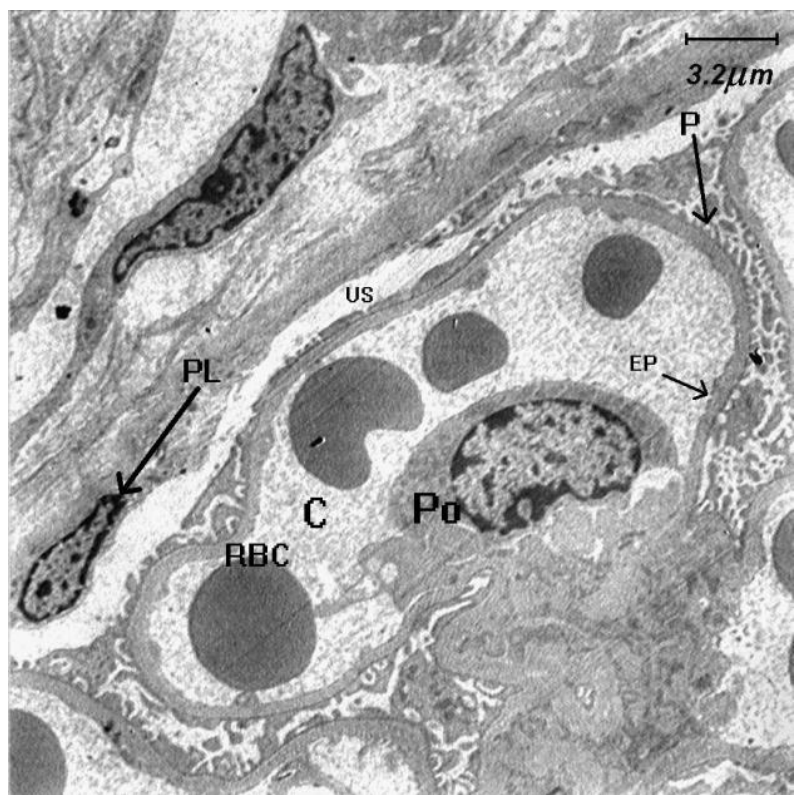

Fig (5): Transmission electron micrograph of the Bowman's capsule of hedgehog. Podocyte (Po) cover the capillary $(C)$; foot processes of podocyte $(P)$; endothelial pores of capillary (EP); red blood cell (RBC); parietal layer of simple squamous epithelial layer (PL), urinary space (US).

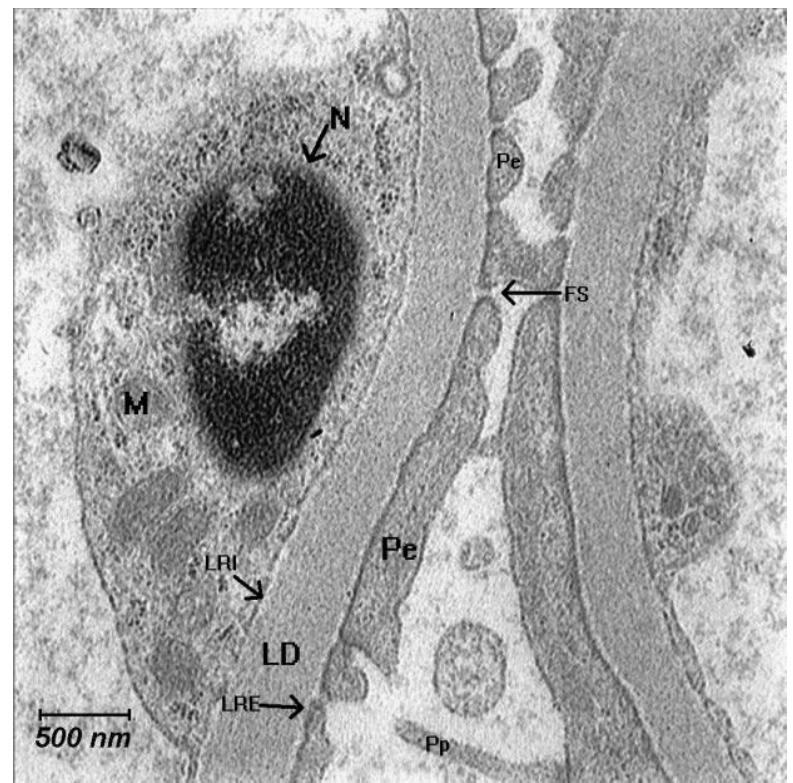

Fig (6): Transmission electron micrograph of podocytes in hedgehog. Nucleus (N); mitochondria (M); filtration slits (FS); pedicles (Pe), secondary podocyte process (Pp); lamina rara externa (LRE); lamina rara interna (LRI)' lamina densa (LD). 


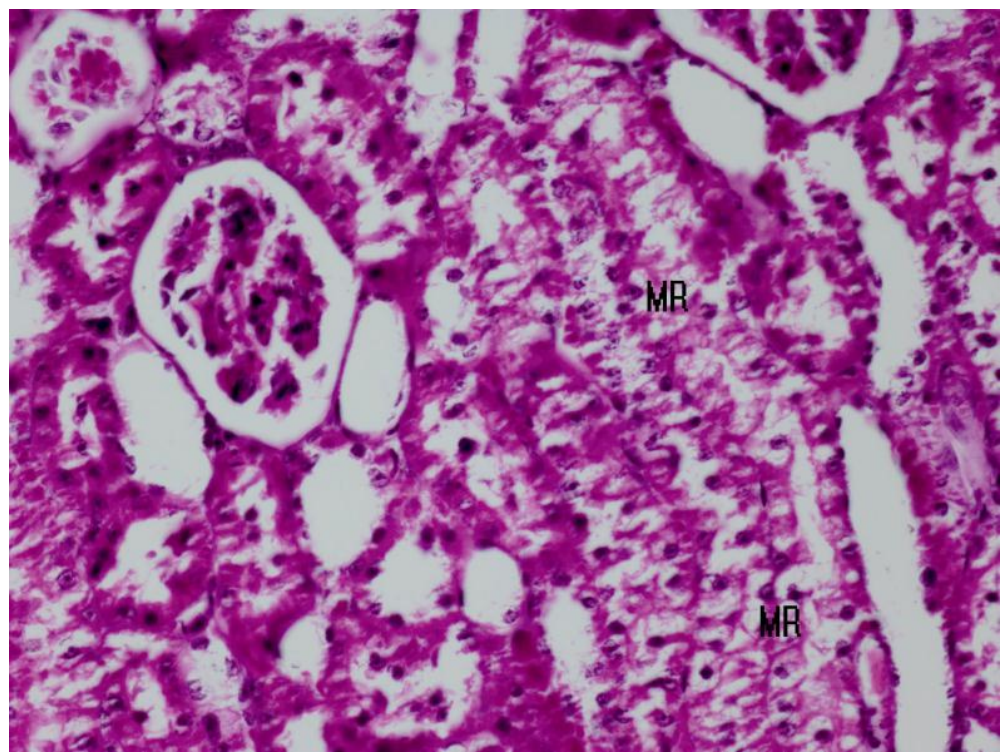

Fig (7): Light micrograph of the cortical labyrinth and medullary ray (MR) within the hedgehog's kidney. Hematoxylin and Eosin stain, $\times 640$.

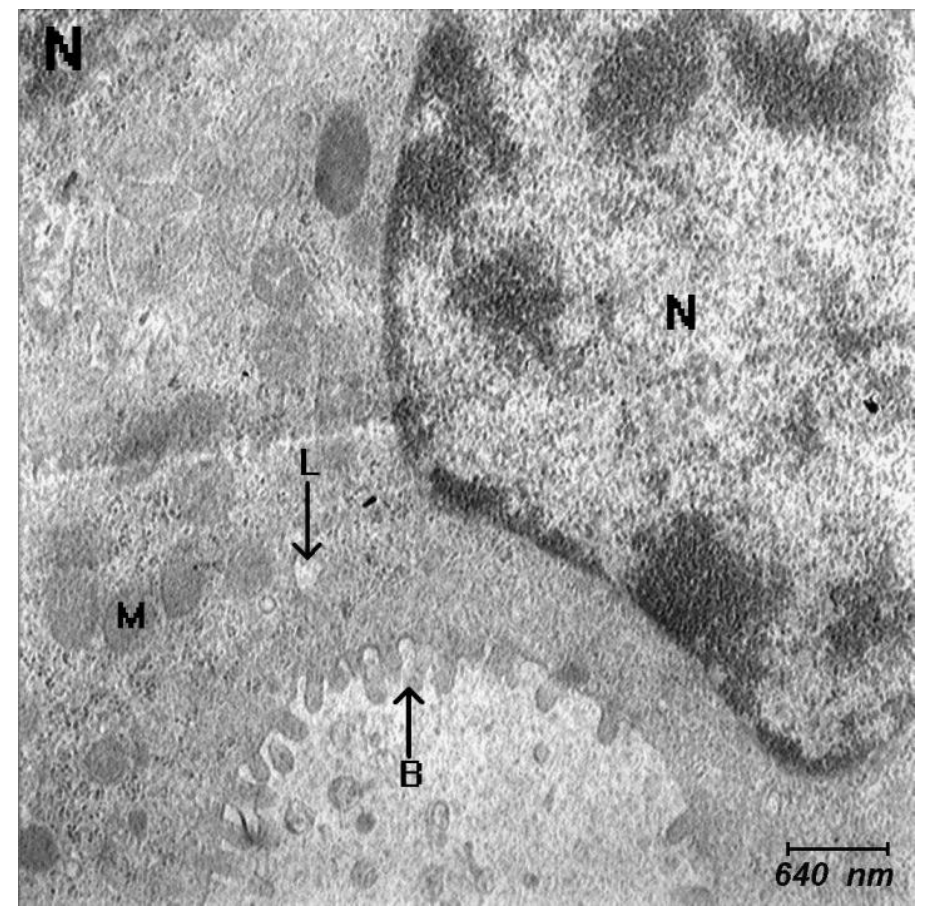

Fig (8): Electron micrograph of a proximal convoluted tubule in hedgehog. Nucleus (N); brush border (B); mitochondria (M), lysosome (L). 


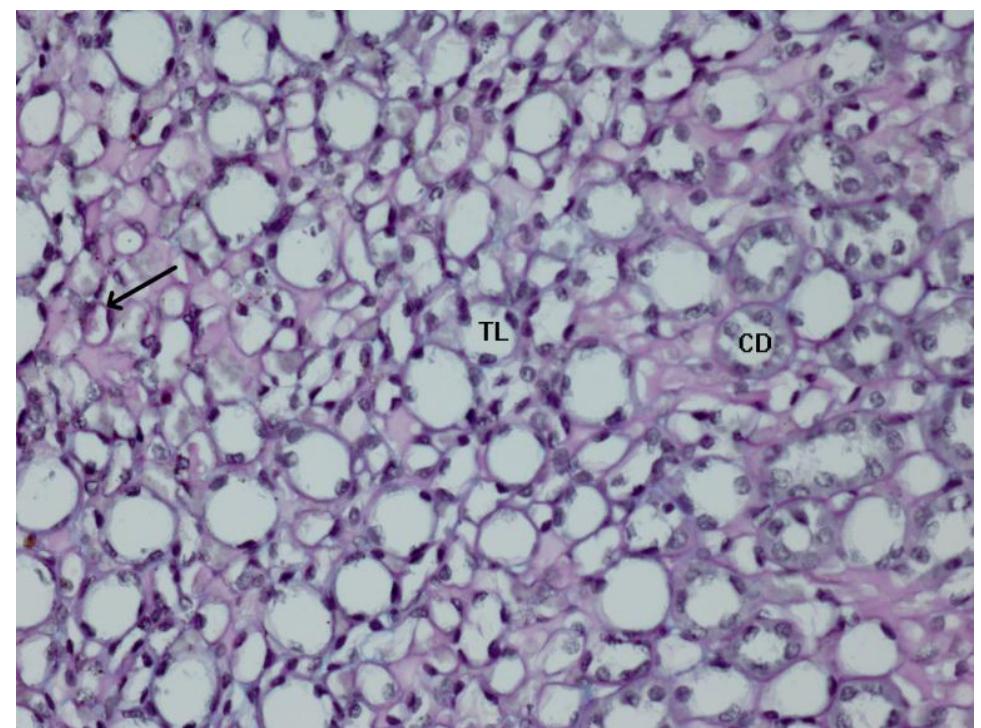

Fig (9): Light micrograph of the medulla of the hedgehog's kidney. Thin limb of the loop of Henle (TL), collecting duct (CD), capillary (arrow). PAS-Alciane blue stain, $x 640$.

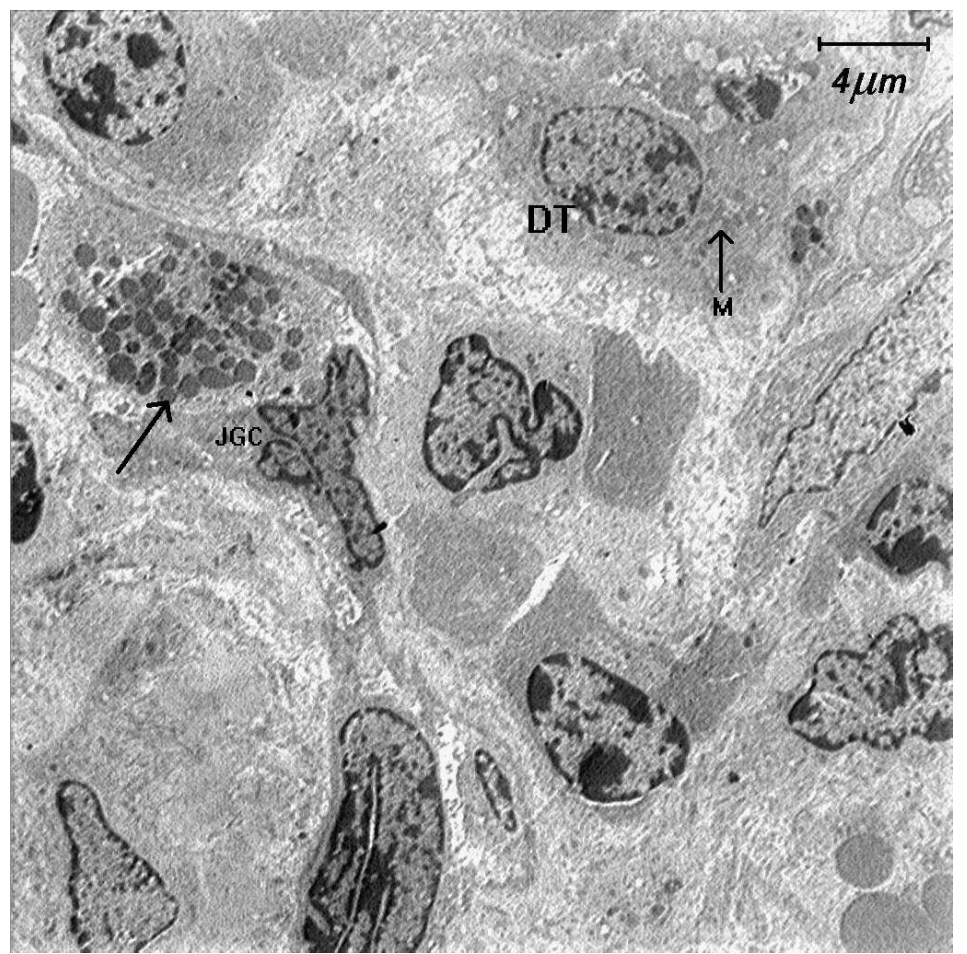

Fig (10): Transmission electron micrograph of the association of the distal convoluted tubule with a juxtaglomerular cell (JGC) with rennin-filled granules (arrow). Cell of the distal convoluted tubule (DT), mitochondria (M). 


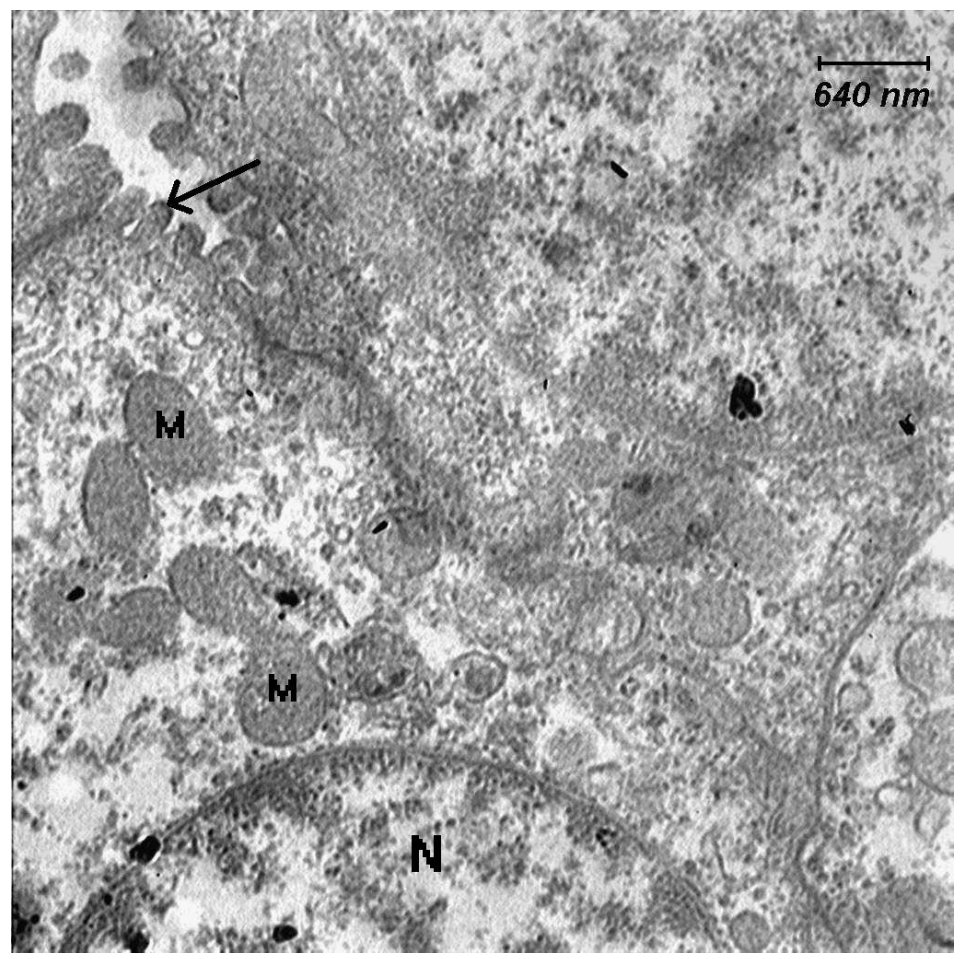

Fig (11): Transmission electron micrograph of the cells of the medullary collecting duct in the kidney of the hedgehog. Nucleus $(\mathrm{N})$; mitochondria $(\mathrm{M})$, microprojections (arrow). 